\title{
The preparation and physicochemical characterization of eprosartan mesylate-laden polymeric ternary solid dispersions for enhanced solubility and dissolution rate of the drug
}

\author{
Abid Mehmood Yousaf ${ }^{1, A, C, D}$, Sundas Zulfiqar ${ }^{2, B}$, Yasser Shahzad ${ }^{1, C, E}$, Talib Hussain ${ }^{1, E}$, Tariq Mahmood ${ }^{2, C, E}$, Muhammad Jamshaid ${ }^{2, F}$ \\ ${ }^{1}$ Department of Pharmacy, COMSATS University Islamabad, Lahore Campus, Pakistan \\ ${ }^{2}$ Faculty of Pharmacy, University of Central Punjab, Lahore, Pakistan \\ A - research concept and design; $\mathrm{B}$ - collection and/or assembly of data; $\mathrm{C}$ - data analysis and interpretation; \\ $D$ - writing the article; $E$ - critical revision of the article; $F$ - final approval of the article
}

Address for correspondence

Abid Yousaf

E-mail: abid.ucp@hotmail.com

Funding sources

None declared

Conflict of interest

None declared

Acknowledgements

The authors are thankful to the University of Central Punjab and to the COMSATS University Islamabad for providing all the materials and the laboratory facility for this research.

Received on April 19, 2018

Reviewed on December 5, 2018

Accepted on January 16, 2019

Cite as

Tousaf AM, Zulfiqar S, Shahzad Y, Hussain T, Mahmood T, Jamshaid M. The preparation and physicochemical characterization of eprosartan mesylate-laden polymeric ternary solid dispersions for enhanced solubility and dissolution rate of the drug. Polim Med. 2018;48(2):69-75. doi:10.17219/pim/102976

D0I

10.17219/pim/102976

Copyright

○) 2019 by Wroclaw Medical University

This is an article distributed under the terms of the

Creative Commons Attribution Non-Commercial Licens

(http://creativecommons.org/licenses/by-nc-nd/4.0/)

\section{Abstract}

Background. Eprosartan mesylate is a poorly water-soluble drug. It does not dissolve well in the aqueous gastrointestinal fluid, which means it is not absorbed well via the oral route, because a drug can cross cell membranes when it is dissolved in the gastrointestinal fluid.

Objectives. The purpose of this research was to enhance the aqueous solubility and dissolution rate of eprosartan mesylate using the solid dispersion technique. Enhancing the solubility and dissolution leads to better absorption via the oral route.

Material and methods. A number of eprosartan mesylate-laden polymeric solid dispersions were prepared with hydroxypropyl methylcellulose (HPMC) and polysorbate 80 by means of the solvent evaporation technique. The impact of the weight ratios of the constituents on the solubility and dissolution rate was studied in comparison with the plain drug. The formulation presenting the optimal solubility and dissolution underwent the solid-state characterization using X-ray diffraction (XRD), differential scanning calorimetry (DSC), scanning electron microscopy (SEM), and Fourier-transform infrared spectroscopy (FTIR).

Results. Both polysorbate 80 and HPMC positively affected the solubility and dissolution of eprosartan mesylate.

Conclusions. In particular, a ternary solid dispersion consisting of eprosartan mesylate, HPMC and polysorbate 80 at a weight ratio of 1:4.2:0.3 showed the highest solubility $(36.39 \pm 3.95 \mathrm{mg} / \mathrm{mL}$ ) and dissolution ( $86.19 \pm 4.09 \%$ in $10 \mathrm{~min})$. Moreover, the drug was present in the amorphous form in the solid dispersion with no covalent drug-excipient interactions.

Key words: amorphous, hydroxypropyl methylcellulose, aqueous solubility, eprosartan mesylate, polymeric solid dispersions 


\section{Introduction}

Eprosartan mesylate, a monomethanesulfonate of $(E)-2$ butyl-1-( $p$-carboxybenzyl)- $\alpha$-2-thienylmethylimid-azole5 -acrylic acid, ${ }^{1}$ is a water-insoluble crystalline powder. ${ }^{2}$ It is considered a promising angiotensin II receptor antagonist. ${ }^{3}$ It is usually prescribed at a dose of 400-800 mg once or twice daily for 13 weeks to patients with mild to severe hypertension. ${ }^{4}$ Unlike angiotensin-converting enzyme inhibitors, it does not induce coughing and has no severe drug interactions. ${ }^{5}$

As a poorly water-soluble drug (its solubility in water is $<1 \mathrm{mg} / \mathrm{mL}$ at $25^{\circ} \mathrm{C}$ ), eprosartan mesylate is categorized in class 2 of the Biopharmaceutics Classification System (BCS). The oral bioavailability of a BCS class 2 drug can be enhanced by ameliorating its aqueous solubility using a solubility-enhancing technique such as solid dispersion. ${ }^{6}$ As its efficacy is very low, eprosartan mesylate is administered in high doses. ${ }^{7,8}$ Improving the solubility of eprosartan mesylate in water might improve its oral efficacy and circumvent the need for high doses.

Several techniques, such as micronization, nanoparticle formation, solubilization with surfactants, microemulsions, complexation with cyclodextrins, encapsulation with hydrophilic polymeric wall materials, self-emulsifying drug delivery systems, and dispersing hydrophobic drugs in hydrophilic polymeric matrices, have been successfully employed to improve the aqueous solubility and dissolution of poorly water-soluble drugs.

Solid dispersion - the dispersal of a hydrophobic drug in a hydrophilic polymer with or without the addition of a surfactant - is an excellent strategy to enhance the solubility and dissolution of water-insoluble drugs. ${ }^{9-19}$ A solid dispersion prepared with the addition of a surfactant (a ternary solid dispersion) results in greater improvement of the solubility and dissolution of BCS class 2 drugs as compared to solid dispersions prepared without a surfactant (binary solid dispersions). ${ }^{20}$ Solid dispersions can be prepared conventionally by the melting method, ${ }^{21}$ the kneading method, ${ }^{22}$ the solvent evaporation method, ${ }^{9}$ or the lyophilization technique. ${ }^{23}$ The use of solid dispersions manufactured by the solvent evaporation method is among the most promising ways to enhance the solubility and dissolution rates of water-insoluble chemical entities, due to the molecular-level closeness of the drug to the hydrophilic carriers, which improves wetting, and the conversion of the crystalline components into their respective amorphous forms, which enhances the surface area exposed to the surrounding dissolution medium. ${ }^{18,24}$

In the present study, a number of eprosartan mesylateladen ternary solid dispersions were prepared with hydroxypropyl methylcellulose (HPMC) and polysorbate 80 by the solvent evaporation method. The aqueous solubility and dissolution of the drug in the solid dispersions were determined. The structural, thermal, morphological, and spectroscopic characteristics of the solid disper- sion exhibiting the best solubility and dissolution were determined using X-ray diffraction (XRD), differential scanning calorimetry (DSC), scanning electron microscopy (SEM), and Fourier-transform infrared spectroscopy (FTIR), respectively.

\section{Material and methods}

\section{Material}

Eprosartan mesylate was supplied by the Jinan Chenghui-Shuangda Chemical Co., Ltd. (Jinan, China). Polyvinylpyrrolidone (PVP), sodium lauryl sulfate (SLS), carboxymethylcellulose sodium (CMC-Na), and 2-hydroxypropyl-beta-cyclodextrin (HP- $\beta-\mathrm{CD})$ were from Sigma-Aldrich (St. Louis, USA). Poly-oxyethylene esters of 12-hydroxystearic acid (Solutol ${ }^{\circledR}$ HS 15), poloxamer 188 and poloxamer 407 were procured from BASF (Ludwigshafen am Rhein, Germany). Gelatin, polyethylene glycol 6000 (PEG-6000), polysorbate 20 (tween 20), polysorbate 60 (tween 60), polysorbate 80 (tween 80 ), sorbitan monolaurate 20 (span 20), and sorbitan monooleate 80 (span 80) were obtained from Daejung Chemicals \& Metals Co., Ltd. (Siheung, South Korea). Hydroxypropyl methylcellulose and dextran were bought from Shin-Etsu Chemical Co., Ltd. (Tokyo, Japan). Carbopol ${ }^{\circledR} 941$ was from Lubrizol Corp. (Wickliffe, USA). All other materials were of the reagent grade.

\section{Method of preparation}

For each solid dispersion formulation, exactly weighed amounts of eprosartan mesylate, HPMC and polysorbate 80 were completely dissolved in $80 \%(\mathrm{v} / \mathrm{v})$ aqueous ethanol to make a transparent solution. These solutions were dried in a tray dryer at $40^{\circ} \mathrm{C}$ until a constant weight was achieved. The dried mass was pulverized and passed through a sieve 60. The solid dispersions were stored in an air-tight 45-milliliter conical tube. The composition of the various solid dispersions is shown in Table 1.

Table 1. The compositions (w/w/w) of the eprosartan mesylate-laden polymeric solid dispersions used in the study

\begin{tabular}{|l|c|l|l|l|l|l|l|}
\multicolumn{1}{|c}{ Components $[\mathrm{g}]$} & $\mathrm{I}$ & $\mathrm{II}$ & $\mathrm{III}$ & $\mathrm{IV}$ & $\mathrm{V}$ & $\mathrm{V}$ I & VII \\
\hline Eprosartan mesylate & 1.0 & 1.0 & 1.0 & 1.0 & 1.0 & 1.0 & 1.0 \\
HPMC & 1.0 & 0.9 & 0.8 & 0.7 & 2.1 & 4.2 & 5.6 \\
Polysorbate 80 & 0 & 0.1 & 0.2 & 0.3 & 0.3 & 0.3 & 0.3 \\
\hline
\end{tabular}

HPMC - hydroxypropyl methylcellulose.

\section{Solubility test}

Excess of the solid dispersion was added to $1 \mathrm{~mL}$ of distilled water in a 2-milliliter microtube and vortexed for $1 \mathrm{~min}$. Each sample was placed in a water bath $\left(25^{\circ} \mathrm{C}\right)$ and agitated (100 rpm) for 5 days. Then, after centrifugation 
$(5000 \mathrm{~g}), 0.5 \mathrm{~mL}$ of the supernatant was carefully taken using a micropipette and appropriately diluted with ethanol. The diluent was analyzed using a HALO DB-20 UV-visible spectrophotometer (Dynamica Scientific, Ltd., Clayton, Australia) at a wavelength of $233 \mathrm{~nm}$ to determine the concentration of eprosartan mesylate.

\section{Drug content determination}

For each formulation, a carefully weighed quantity, equivalent to $50 \mathrm{mg}$ of eprosartan mesylate, was dissolved in $100 \mathrm{~mL}$ of $80 \%(\mathrm{v} / \mathrm{v})$ aqueous ethanol in a $100-\mathrm{milli}-$ liter measuring flask. Thus, the theoretical concentration of the stock solution was $500 \mu \mathrm{g} / \mathrm{mL}$. The solution was strained through a $0.45 \mu \mathrm{m}$ pore-sized syringe filter and the filtrate was diluted appropriately with ethanol. Then, using the HALO DB-20 UV-visible spectrophotometer, the diluted sample was analyzed at a wavelength of $233 \mathrm{~nm}$ to calculate the concentration of eprosartan mesylate. The experiment was carried out in triplicate for each formulation. The eprosartan mesylate content was determined by the following formula:

$$
X_{s}=X_{a} / X_{t} \times 100
$$

where

$X_{s}$ - the content of eprosartan mesylate [\%];

$X_{a}$ - the actual titer, quantified through the UV-visible spectrophotometer $[\mu \mathrm{g} / \mathrm{mL}]$;

$X_{t}$ - the theoretical concentration $[\mu \mathrm{g} / \mathrm{mL}]$.

\section{Dissolution test}

Dissolution was investigated using a USP Dissolution Apparatus 2 (Vision ${ }^{\circledR}$ Classic $6^{\mathrm{TM}}$; Hanson Research Corp., Los Angeles, USA). Each sample, equivalent to $50 \mathrm{mg}$ of eprosartan mesylate, was added to $900 \mathrm{~mL}$ of a dissolution medium containing $1 \%(\mathrm{w} / \mathrm{v})$ SLS. ${ }^{25,26}$ The dissolution medium was kept at $37 \pm 0.5^{\circ} \mathrm{C}$ by a surrounding water bath. The paddle was fixed at a rotation speed of $100 \mathrm{rpm} .{ }^{19}$ At each predetermined time point, $1 \mathrm{~mL}$ of the dissolution medium was sampled, filtered (a pore size of $0.45 \mu \mathrm{m}$ ) and diluted adequately. After each sampling, the dissolution medium was immediately replenished with the pre-warmed dissolution medium to maintain the sink conditions. The diluted samples were examined by the HALO DB-20 UV-visible spectrophotometer at a wavelength of $233 \mathrm{~nm}$.

\section{Powder X-ray diffraction}

The crystallinity or amorphousness of the samples was assessed using a Rigaku X-ray diffractometer (D/MAX2500 PC; Rigaku Corp., Tokyo, Japan). The X-ray diffraction analysis was completed using the $\mathrm{Cu} K \alpha_{1}$ monochromatic radiation source at a voltage of $50 \mathrm{kV}$ and a current of $100 \mathrm{~mA}$. The powder XRD (PXRD) results were recorded in the $10-70^{\circ}$ range in the $2 \theta$ scanning mode, at a scan speed of $5 \% \mathrm{~min}$ and a step size of $0.02 \%$.

\section{Differential scanning calorimetry}

Differential scanning calorimetry was used as a confirmatory test for the change of the crystalline form of eprosartan mesylate to the amorphous form in the optimal formulation. Hydroxypropyl methylcellulose, the eprosartan mesylate powder, a physical blend and the optimized solid dispersion formulation were analyzed using a differential scanning calorimeter DSC Q20 (TA Instruments, New Castle, USA). The physical mixture was obtained by mixing eprosartan mesylate, HPMC and polysorbate 80 , in the same weight ratio as in the optimal formulation, using a mortar and a pestle. About $10 \mathrm{mg}$ of each sample was tightly enclosed in the aluminum sample pan and heated at $15^{\circ} \mathrm{C} / \mathrm{min}$ in the calorimeter. The test was executed in the range of $30-300^{\circ} \mathrm{C}$ in the presence of nitrogen gas flowing at a rate of $30 \mathrm{~mL} / \mathrm{min}$.

\section{Scanning electron microscopy}

The evaluation of the morphology of the pure eprosartan mesylate powder, HPMC and the optimal solid dispersion was performed using an S-4800 scanning electron microscope (Hitachi, Ltd., Tokyo, Japan). All the samples were coated with platinum and inspected under the electron microscope. Platinum coating is necessary for proper visibility and imaging of the samples; without it, samples are either invisible or extremely blurry.

\section{Fourier-transform infrared spectroscopy}

A Nicolet 6700 spectrophotometer (Thermo Fisher Scientific, Inc., Waltham, USA) was used for the FTIR analyses of the optimal formulation, the physical mixture and the individual components. Each sample was appropriately mounted on the sample disc under the scanning pin and viewed from $600 \mathrm{~cm}^{-1}$ to $4000 \mathrm{~cm}^{-1}$ using a resolution of $2 \mathrm{~cm}^{-1}$.

\section{Statistical methods}

In the solubility test, 3 samples were analyzed for each polymer, surfactant and formulation. The mean value and standard deviation (SD) were determined using MS Excel software (Microsoft Corp., Redmond, USA). During the dissolution test, 6 samples were taken at specified time points for each formulation, and the mean value and SD were determined. Moreover, values of percent dissolved obtained at a specific time point for the optimal formulation were compared with the corresponding values of each formulation separately, using the t-test. A p-value of 0.05 was taken as the threshold of statistical significance. 


\section{Results and discussion}

First, to select the most appropriate excipients for a ternary solid dispersion, the solubility of eprosartan mesylate was determined in $1 \%(\mathrm{w} / \mathrm{v})$ aqueous solutions of each surfactant and hydrophilic polymer. The hydrophilic polymer and surfactant in which the drug exhibited the highest apparent solubility were selected for the preparation of solid dispersions. Eprosartan mesylate showed the highest solubility in HPMC $(514.43 \pm 3.53 \mu \mathrm{g} / \mathrm{mL})$ and polysorbate 80 $(513.64 \pm 0.12 \mu \mathrm{g} / \mathrm{mL})$ among the polymers and surfactants, respectively; therefore, they were selected as the most appropriate constituents for the solid dispersion formulation in this study (Fig. 1A and 1B, respectively).

The solvent evaporation method is considered one of the most promising methods for the preparation of solid dispersions in terms of the enhancement of solubility,
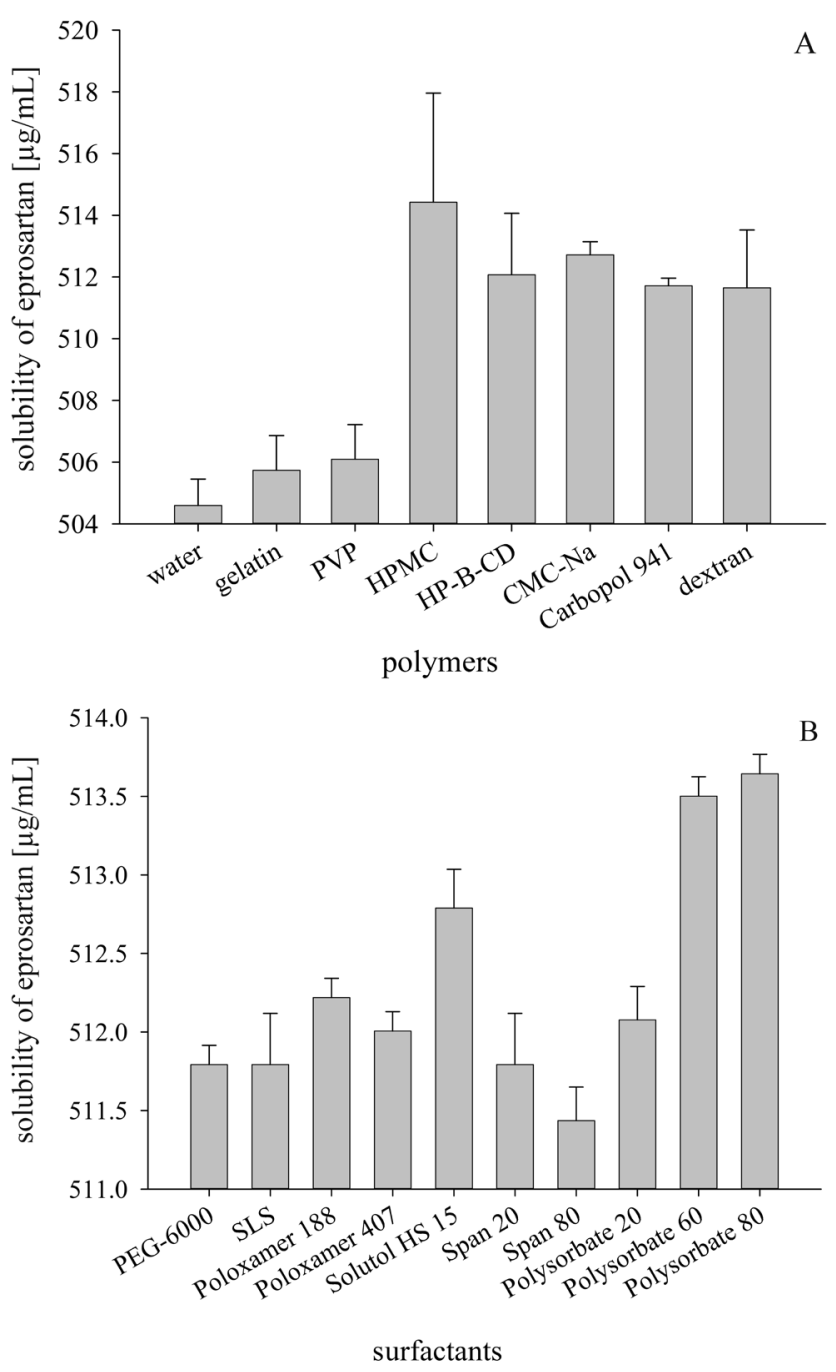

Fig. 1. The solubility of eprosartan mesylate in $1 \%(\mathrm{~W} / \mathrm{V})$ aqueous solution of various carriers: hydrophilic polymers (A) and surfactants (B). Each value denotes the mean \pm standard deviation (SD) of 3 trials

CMC-Na - carboxymethylcellulose sodium; HP- $\beta-C D$ - 2-hydroxypropylbeta-cyclodextrin; PEG-6000 - polyethylene glycol 6000; PVP - polyvinylpyrrolidone; SLS - sodium lauryl sulfate; Solutol HS 15 - poly-oxyethylene esters of 12-hydroxystearic acid; span 20 - sorbitan monolaurate 20; span 80 - sorbitan monooleate 80. dissolution and oral bioavailability. ${ }^{9,18}$ In this method, the drug and the excipients are completely dissolved in a solvent before drying to achieve molecular-level mixing. Therefore, all the components are homogeneously present and closely combined in the dried product. This improves wetting and enhances the surface area of the drug by converting it to its amorphous counterpart, as the polymeric matrix prevents the recrystallization of the drug. Normally, during the drying process, the dissolved crystalline drug tends to recrystallize from the solution, ${ }^{27}$ but this tendency is inhibited when polymeric matrices are present in the solution. ${ }^{28,29}$ In such cases, recrystallization is either circumvented completely or crystalline intensity is diminished considerably. ${ }^{18,27}$ Both the type ${ }^{30}$ and quantity $^{31,32}$ of the polymeric matrix play a role in exerting this inhibitory effect on recrystallization. The homogeneity of the products was reflected by the high drug content, which was $99-101 \%$ in all formulations in this study. The solvent evaporation method was therefore adopted in our study.

All the 7 formulations showed better solubility and dissolution than plain eprosartan mesylate (Fig. 2A and 2B, respectively). The solubility for each formulation was as follows: I - $3.06 \pm 0.80 \mathrm{mg} / \mathrm{mL}$; II $-7.69 \pm 1.93 \mathrm{mg} / \mathrm{mL}$; III - $14.25 \pm 4.11 \mathrm{mg} / \mathrm{mL}$; IV $-23.00 \pm 3.34 \mathrm{mg} / \mathrm{mL}$; $\mathrm{V}-34.98 \pm 3.42 \mathrm{mg} / \mathrm{mL}$; VI $-36.39 \pm 3.95 \mathrm{mg} / \mathrm{mL}$; and VII $-32.01 \pm 3.92 \mathrm{mg} / \mathrm{mL}$. The dissolution at $10 \mathrm{~min}$ was: I $-8.94 \pm 0.70 \%$; II $-23.95 \pm 3.87 \%$; III $-35.40 \pm 3.57 \%$; IV - $55.27 \pm 8.02 \%$; V - $85.48 \pm 10.16 \%$; VI - 86.19 $\pm 4.09 \%$; and VII $-84.24 \pm 5.20 \%$. As the quantity of the surfactant increased in formulations I-IV, the solubility and dissolution were improved. This enhanced solubility can be accredited to the solubilizing power of polysorbate 80 . Formulation IV was then selected, and the further effect of HPMC on solubility and dissolution was investigated. Hydroxypropyl methylcellulose improved the aqueous solubility and dissolution as compared to formulation IV. This further improvement can be ascribed to the hydrophilic polymer increasing the wettability of the drug. In particular, formulation VI showed the highest solubility and dissolution; however, the values of formulations V-VII did not significantly differ from one another. The solubility of formulation VI was also higher than the solubility of the corresponding physical mixture $(36.39 \pm 3.95 \mathrm{mg} / \mathrm{mL}$ vs $19.98 \pm 7.98 \mathrm{mg} / \mathrm{mL}$, respectively). Moreover, the dissolution rate of eprosartan mesylate with solid dispersion formulation VI was more rapid than the rates achieved by the solid dispersions discussed in some recent studies. ${ }^{33,34}$ As compared to formulation VI, the dissolution profile of the corresponding physical mixture was inferior and erratic. This behavior can be ascribed to the presence of the crystalline form of the drug and the heterogeneity of the physical mixture. In consequence, on the grounds of the highest apparent solubility and excellent dissolution, formulation VI was selected as the optimal formulation in this study. 

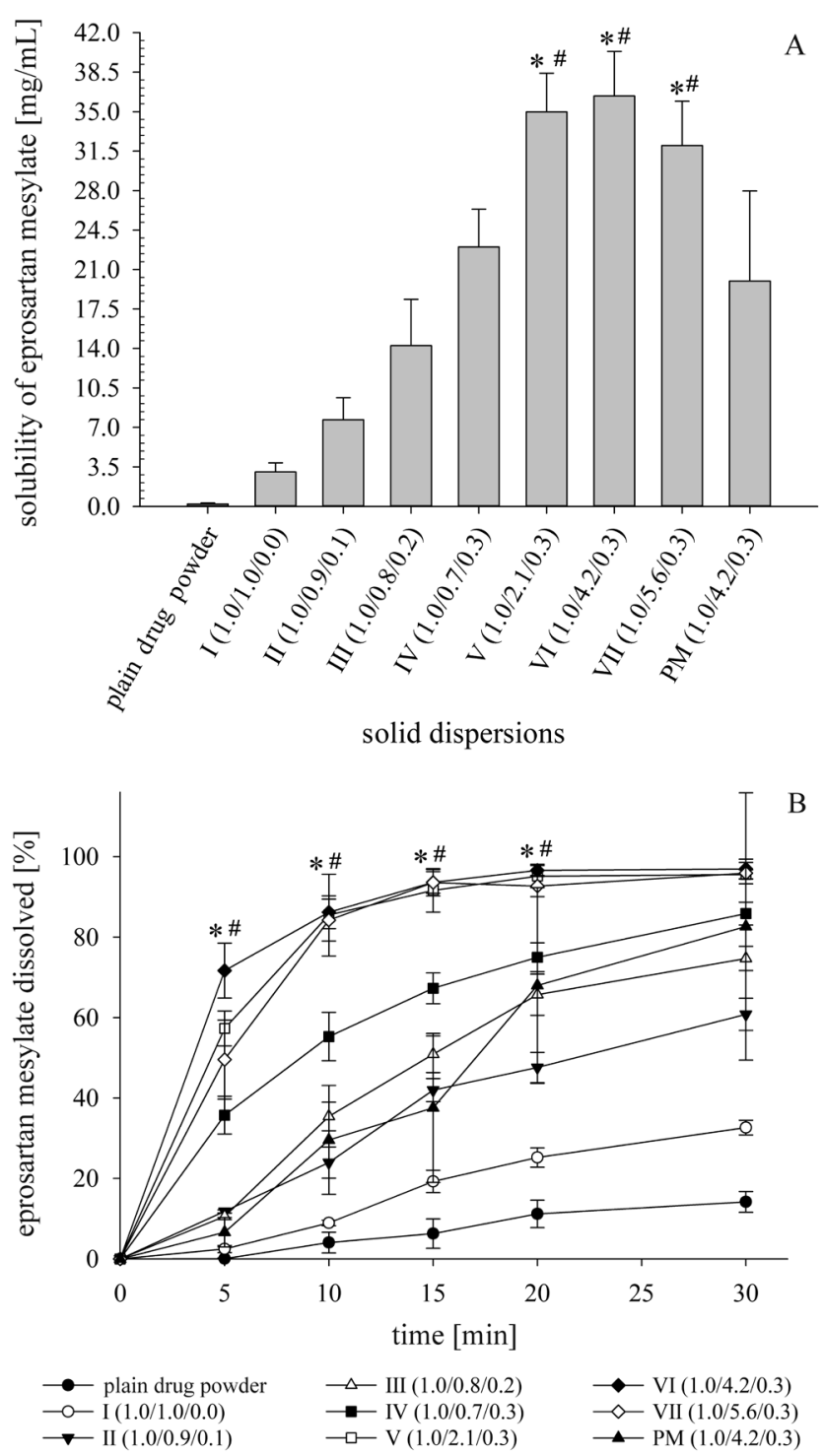

Fig. 2. The effect of polysorbate $80(I-I V)$ and HPMC (V-VII) on the aqueous solubility (A) and dissolution (B) of eprosartan mesylate in solid dispersions; the solubility and dissolution of the drug in a physical mixture (PM) is also shown. Each value denotes the mean \pm SD of 3 solubility trials and 6 dissolution trials

${ }^{*} p<0.05$ compared with the plain drug powder and formulations I-IV; \# $p>0.05$ compared with formulations V-VII.

The XRD pattern of eprosartan mesylate showed typical crystalline peaks (Fig. 3A). Hydroxypropyl methylcellulose was amorphous; no sharp crystalline peaks appeared (Fig. 3B). Eprosartan mesylate-related peaks were also observed observed in the pattern of the physical mixture (Fig. 3C). In contrast, eprosartan was converted into the amorphous state in solid dispersion formulation VI (Fig. 3D), as no sharp peaks were seen, unlike the pattern of the physical mixture.

Similarly, the DSC curve of eprosartan mesylate showed a deep endotherm at about $251^{\circ} \mathrm{C}$ at its melting point (Fig. 4A), confirming its typical crystalline nature. No sharp endotherm appeared in the thermogram of HPMC, due to its amorphousness (Fig. 4B). However, a broad endothermic slide was seen between $40^{\circ} \mathrm{C}$ and $175^{\circ} \mathrm{C}$.

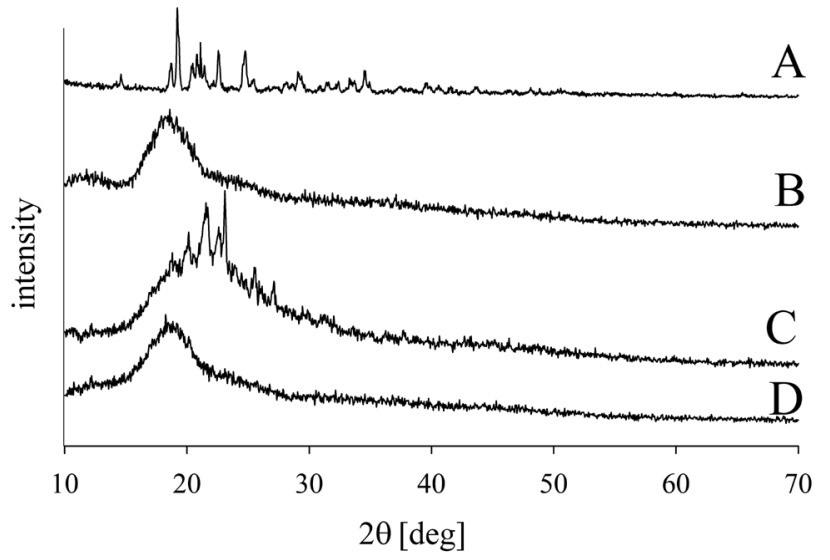

Fig. 3. X-ray diffraction (XRD) patterns: eprosartan mesylate (A), HPMC (B), the physical mixture (C), and solid dispersion $\mathrm{VI}(\mathrm{D})$

An eprosartan-related endotherm was observed in the thermogram of the physical mixture (Fig. 4C); however, there was no endotherm in the thermogram of solid dispersion formulation VI (Fig. 4D). This confirmed that the drug was present in the crystalline state in the physical mixture, but was changed to the amorphous form in the solid dispersion. Thus, the DSC results were in harmony with the XRD patterns.

The shapes and surfaces of the particles of eprosartan mesylate (Fig. 5A), HPMC (Fig. 5B) and formulation VI (Fig. 5C) were observed by means of SEM. The plain eprosartan mesylate powder consisted of rod-shaped crystals with very rough surfaces. The particles of HPMC had irregular shapes and surfaces. The particles of formulation VI appeared as flakes.

In the FTIR spectrum, the chief distinctive peaks of eprosartan mesylate were at $743 \mathrm{~cm}^{-1}, 772 \mathrm{~cm}^{-1}, 830 \mathrm{~cm}^{-1}$, $849 \mathrm{~cm}^{-1}$, and $1154 \mathrm{~cm}^{-1}$ (Fig. 6A). These peaks were also clearly seen in the spectrum of the physical mixture (Fig. 6C). The spectrum of solid dispersion formulation VI (Fig. 6D) overlapped that of the physical mixture; the chief distinguishing peaks did not shift. This suggests that eprosartan mesylate has no strong bonding with the excipients.

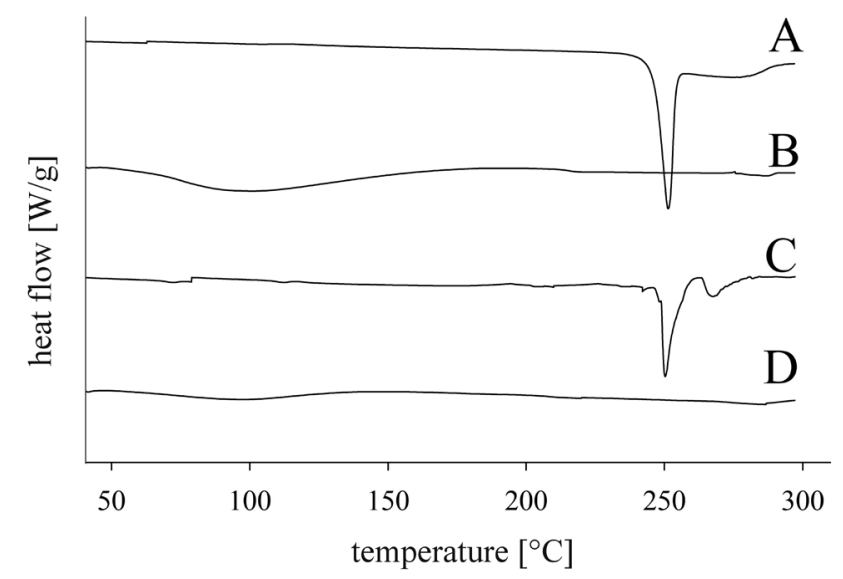

Fig. 4. Differential scanning calorimetry (DSC) thermograms: eprosartan mesylate (A), HPMC (B), the physical mixture (C), and solid dispersion VI (D) 

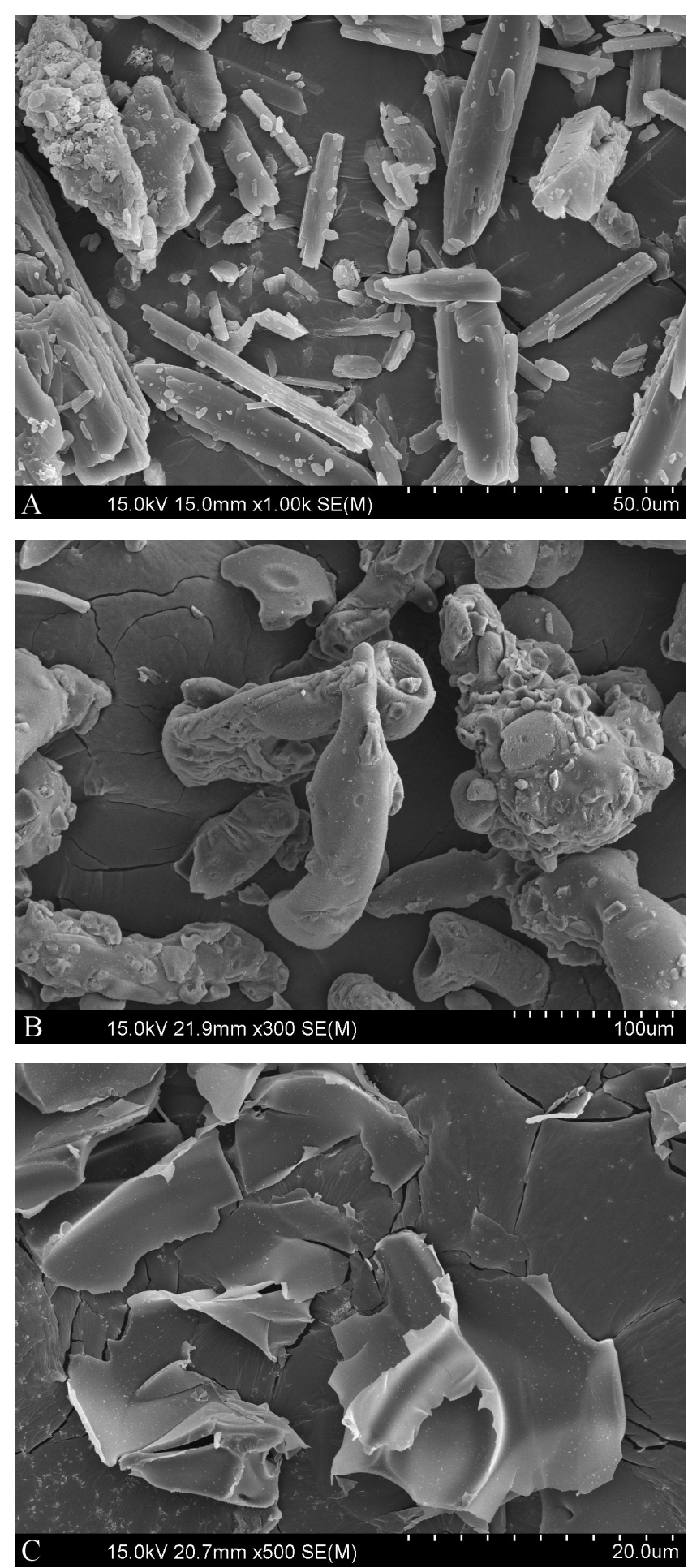

Fig. 5. Scanning electron microscopy (SEM) images: eprosartan mesylate $(\times 1000)(A), H P M C(\times 300)(B)$ and solid dispersion VI (×500) (C)

\section{Conclusions}

Solid dispersion formulation VI, containing eprosartan mesylate, HPMC and polysorbate 80 at a ratio of 1.0/4.2/0.3 (w/w/w), showed the highest solubility $(36.39 \pm 3.95 \mathrm{mg} / \mathrm{mL})$ and dissolution ( $86.19 \pm 4.09 \%$ in $10 \mathrm{~min}$ ) among all the samples tested. The solubility was approx. 170 times higher than the solubility of the plain drug powder $(36.39 \pm 3.95 \mathrm{vs}$

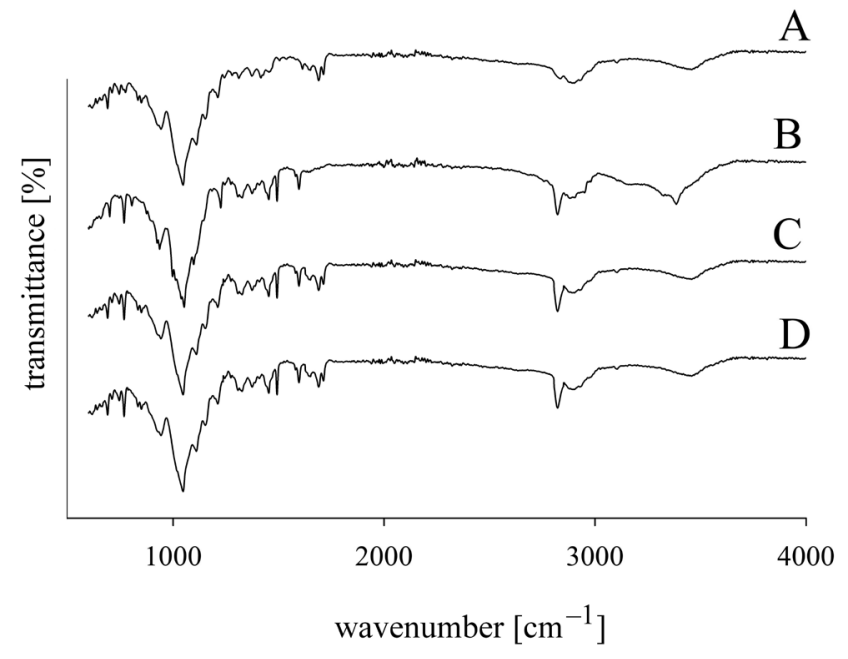

Fig. 6. Fourier-transform infrared spectroscopy (FTIR) spectra: eprosartan mesylate (A), HPMC (B), the physical mixture (C), and solid dispersion VI (D)

$0.21 \pm 0.10 \mu \mathrm{g} / \mathrm{mL}$, respectively). Moreover, eprosartan mesylate was in the amorphous state in solid dispersion formulation VI, as shown by XRD and confirmed by DSC. Also, no covalent bonding existed between the drug and the ex cipients, as shown by the FTIR spectra. The particles of the formulation had irregular shapes and surfaces, and appeared as flakes. In view of the above, this formulation might be an effective system for the oral delivery of eprosartan mesylate with improved solubility and dissolution.

\section{ORCID iDs}

Abid Mehmood Yousaf (i) https://orcid.org/0000-0001-7866-9474 Sundas Zulfiqar (1) https://orcid.org/0000-0001-7579-7307 Yasser Shahzad (10) https://orcid.org/0000-0002-0974-2954 Talib Hussain (1) https://orcid.org/0000-0002-0465-9713 Tariq Mahmood (1) https://orcid.org/0000-0001-7097-5442 Muhammad Jamshaid (1) https://orcid.org/0000-0003-2682-7121

\section{References}

1. Vijaya Santhi D, Reddy NH, Sumalatha N, Jothieswari D. A novel estimation of eprosartan mesylate in pure and in tablet formulations by simple UV method. Res J Pharm Technol. 2011;4(7):1069-1072.

2. Satheesh B, Pulluru SK, Nitin K, Saravanan D. Simultaneous determination of eprosartan, hydrochlorothiazide, and their related compounds in pharmaceutical dosage forms by UPLC. J Liq Chromatogr Relat Technol. 2011;34(17):1885-1900.

3. Israili Z. Clinical pharmacokinetics of angiotensin II (AT1) receptor blockers in hypertension. J Hum Hypertens. 2000;14(S1):S73-S86.

4. Hedner T, Himmelmann A; the Eprosartan Multinational Study Group. The efficacy and tolerance of one or two daily doses of eprosartan in essential hypertension. J Hypertens. 1999;17(1):129-136.

5. McClellan KJ, Balfour JA. Eprosartan. Drugs. 1998;55(5):713-718, discussion 719-720.

6. Sareen S, Mathew G, Joseph L. Improvement in solubility of poor water-soluble drugs by solid dispersion. Int J Pharm Investig. 2012;2(1):12-17.

7. Derosa G, Ragonesi P, Mugellini A, Ciccarelli L, Fogari R. Effects of telmisartan compared with eprosartan on blood pressure control, glucose metabolism and lipid profile in hypertensive, type 2 diabetic patients: A randomized, double-blind, placebo-controlled 12-month study. Hypertens Res. 2004;27(7):457-464.

8. Dézsi CA. The different therapeutic choices with ARBs. Which one to give? When? Why? Am J Cardiovasc Drugs. 2016;16(4):255-266. 
9. Joe JH, Lee WM, Park YJ, et al. Effect of the solid-dispersion method on the solubility and crystalline property of tacrolimus. Int J Pharm. 2010;395(1):161-166.

10. Yan YD, Sung JH, Kim KK, et al. Novel valsartan-loaded solid dispersion with enhanced bioavailability and no crystalline changes. Int J Pharm. 2012;422(1-2):202-210.

11. Cho JH, Kim YI, Kim DW, et al. Development of novel fast-dissolving tacrolimus solid dispersion-loaded prolonged release tablet. Eur J Pharm Sci. 2014;54(Suppl C):1-7.

12. Dave $\mathrm{RH}$, Patel HH, Donahue E, Patel AD. To evaluate the change in release from solid dispersion using sodium lauryl sulfate and model drug sulfathiazole. Drug Dev Ind Pharm. 2013;39(10):1562-1572.

13. Hwang du $\mathrm{H}, \mathrm{Kim} \mathrm{Yl}, \mathrm{Cho} \mathrm{KH}$, et al. A novel solid dispersion system for natural product-loaded medicine: Silymarin-loaded solid dispersion with enhanced oral bioavailability and hepatoprotective activity. J Microencapsul. 2014;31(7):619-626.

14. Leane MM, Sinclair W, Qian F, et al. Formulation and process design for a solid dosage form containing a spray-dried amorphous dispersion of ibipinabant. Pharm Dev Technol. 2013;18(2):359-366.

15. Yousaf AM, Kim DW, Kim JO, et al. Characterization of physicochemical properties of spray-dried solid dispersions loaded with unmodified crystalline fenofibrate. Curr Pharm Anal. 2015;11(2):139-144.

16. Shahzad Y, Sohail S, Arshad MS, Hussain T, Shah SNH. Development of solid dispersions of artemisinin for transdermal delivery. Int J Pharm. 2013;457(1):197-205.

17. Yousaf AM, Mustapha O, Kim DW, et al. Novel electrosprayed nanospherules for enhanced aqueous solubility and oral bioavailability of poorly water-soluble fenofibrate. Int J Nanomedicine. 2016;11:213-221.

18. Yousaf AM, Kim DW, Kim DS, et al. Influence of polyvinylpyrrolidone quantity on the solubility, crystallinity and oral bioavailability of fenofibrate in solvent-evaporated microspheres. J Microencapsul. 2016;33(4):365-371.

19. Yousaf AM, Kim DW, Oh YK, Yong CS, Kim JO, Choi HG. Enhanced oral bioavailability of fenofibrate using polymeric nanoparticulated systems: Physicochemical characterization and in vivo investigation. Int J Nanomedicine. 2015;10:1819-1930.

20. Vasconcelos T, Sarmento B, Costa P. Solid dispersions as strategy to improve oral bioavailability of poor water soluble drugs. Drug Discov Today. 2007;12(23):1068-1075.

21. Ming-Thau S, Ching-Min Y, Sokoloski TD. Characterization and dissolution of fenofibrate solid dispersion systems. Int J Pharm. 1994;103(2):137-146.

22. Modi A, Tayade P. Enhancement of dissolution profile by solid dispersion (kneading) technique. AAPS PharmSciTech. 2006;7(3):E87-92.

23. Patel T, Patel L, Patel T, Makwana S, Patel T. Enhancement of dissolution of fenofibrate by solid dispersion technique. Int J Res Pharm Sci. 2010;1(2):127-132.

24. Craig DQ. The mechanisms of drug release from solid dispersions in water-soluble polymers. Int J Pharm. 2002;231(2):131-144.

25. Shah V, Konecny J, Everett R, McCullough B, Noorizadeh AC, Skelly J. In vitro dissolution profile of water-insoluble drug dosage forms in the presence of surfactants. Pharm Res. 1989;6(7):612-618.

26. Shah VP, Noory A, Noory C, et al. In vitro dissolution of sparingly water-soluble drug dosage forms. Int J Pharm. 1995;125(1):99-106.

27. Hugo M, Kunath K, Dressman J. Selection of excipient, solvent and packaging to optimize the performance of spray-dried formulations: Case example fenofibrate. Drug Dev Ind Pharm. 2013;39(2):402-412.

28. Taylor LS, Zografi G. Spectroscopic characterization of interactions between PVP and indomethacin in amorphous molecular dispersions. Pharm Res. 1997;14(12):1691-1698.

29. Doherty C, York P. Accelerated stability of an X-ray amorphous frusemide-polyvinylpyrrolidone solid dispersion. Drug Dev Ind Pharm. 1989;15(12):1969-1987.

30. Konno H, Handa T, Alonzo DE, Taylor LS. Effect of polymer type on the dissolution profile of amorphous solid dispersions containing felodipine. Eur J Pharm Biopharm. 2008;70(2):493-499.

31. Gupta P, Kakumanu VK, Bansal AK. Stability and solubility of celecoxib-PVP amorphous dispersions: A molecular perspective. Pharm Res. 2004;21(10):1762-1769.
32. Tanno F, Nishiyama Y, Kokubo H, Obara S. Evaluation of hypromellose acetate succinate (HPMCAS) as a carrier in solid dispersions. Drug Dev Ind Pharm. 2004;30(1):9-17.

33. Dangre PV, Godbole MD, Ingale PV, Mahapatra DK. Improved dissolution and bioavailability of eprosartan mesylate formulated as solid dispersions using conventional methods. Ind J Pharm Edu Res. 2016;50(3):S209-217.

34. Ahn JS, Kim KM, Ko CY, Kang JS. Absorption enhancer and polymer (vitamin E TPGS and PVP K29) by solid dispersion improve dissolution and bioavailability of eprosartan mesylate. Bull Korean Chem Soc. 2011;32(5):1587-1592. 